\title{
Ocular Echobiometry and Resistivity Index of External Ophthalmic Artery in Agoutis (Dasyprocta prymnolopha)
}

\author{
Sabrina Barros Araújo ${ }^{1}$, Flávio Ribeiro Alves ${ }^{2}$, Gerson Tavares Pessoa ${ }^{3}$, \\ Renan Paraguassu de Sá Rodrigues ${ }^{3}$, Laecio da Silva Moura ${ }^{3}$, Andrezza Braga Soares da Silva ${ }^{3}$, \\ Maria Angélica Parentes da Silva Barbosa ${ }_{\odot}^{4}$, Kassio Vieira Macedo ${ }_{\odot}^{5}$ \& Almir Pereira de Souza ${ }^{1}$
}

\begin{abstract}
Background: Veterinary Ophthalmology provides complementary information for the diagnosis of ocular pathologies. Studies in wild species are essential. Among the diagnostic techniques in ophthalmology, two-dimensional ultrasonography stands out. The agouti is a rodent belonging to the Dasyproctidae family that has been widely used as an experimental model. For these animals, sight is one of the crucial senses for their survival. The aim of this study was to evaluate the effectiveness of the two-dimensional ocular ultrasound technique to obtain anatomical measurements and the external ophthalmic artery resistivity index, presumably normal in the species Dasyprocta prymnolopha.

Materials, Methods \& Results: Forty eye bulbs of 20 adult rodents of the species were evaluated by ultrasonography. In these animals, B-mode echobiometry was performed using the transpalpebral approach and the hemodynamic study of the external ophthalmic artery using the color Doppler technique. All examinations were initiated by the left eye bulb and all measurements were performed by only one examiner. The collected data related to echobiometry were analyzed using Bioest 5.0 for Windows. Initially, normality was tested using the Shapiro-Wilk test for each parameter, then the paired t-test was performed, comparing right and left eyes, and a significance level of 5\% $(P<0.05)$ was adopted. Based on the methodology used, the following values were obtained for the right and left eyeballs, respectively: anterior chamber thickness - mean of $1.28 \pm 0.3 \mathrm{~mm}$ and $1.22 \pm 0.1 \mathrm{~mm}$; lens thickness $-8.27 \pm 0.9 \mathrm{~mm}$ and $8.11 \pm 0.9 \mathrm{~mm}$; vitreous chamber thickness $-5.35 \pm 0.48 \mathrm{~mm}$ and $5.30 \pm 0.47 \mathrm{~mm}$ and axial length $-12.7 \pm 0.9 \mathrm{~mm}$ and $13 \pm 0.68 \mathrm{~mm}$. The mean external ophthalmic artery resistivity values were $0.4305 \pm 0.0390$ and $0.4258 \pm 0.0387$ (right and left eye, respectively), characterizing a low resistance. There was no statistical difference between the right and left eyeballs in any of the studied parameters. Discussion: The use of the convex transducer was feasible, promoting adequate contact with the ocular surface and images of satisfactory quality for obtaining measurements, similar to what was observed in studies evaluating the ocular biometry of primates and dogs. The anterior chamber thickness values in this experiment did not differ statistically between the antimers, as well as observed for dogs. The data obtained for lens thickness did not differ statistically for antimers, like those obtained for other rodent species evaluated with the same methodology. The mean values of vitreous chamber thickness were like those observed in chinchillas but correspond to about half of that obtained for capybaras. In this study, the external ophthalmic artery was characterized in all animals, but obtaining the spectral tracing was difficult due to its fine caliber. In wild animals, and especially in wild rodents, there are few data reporting the resistivity of the ophthalmic artery, and there is a lack of studies, which can be explained by the behavioral characteristics of defense and by the high susceptibility to stress in capture, since the performing the technique requires, as in other procedures, the use of chemical containment.
\end{abstract}

Keywords: Doppler flow, ultrasound, eye, agouti. 


\section{INTRODUCTION}

Veterinary Ophthalmology is the speciality whose studies have been expanded, and requires complementary information for the diagnosis of pathologies, increasingly requiring specialized literature. The constant research on the most varied species is fundamental because it allows the standardization of ophthalmic clinical data, appropriately directing the treatments $[1-3,8]$.

B-mode ultrasound is a useful resource in veterinary medicine and has gained importance. It is a fast and safe technique that provides important and complementary information to the ophthalmic examination, as well as a qualitative and quantitative evaluation of intraocular and orbital lesions [14]. This feature, when applied to wild animals, is particularly important in the diagnosis of ophthalmic pathological changes and determination of normal biometric values [18].

The agouti is a medium-sized rodent that belongs to the Dasyproctidae family and genus Dasyprocta. It is distributed geographically from Central America to South America. Its body is slender, its head is elongated with small ears and its lower limbs are smaller than its hind legs, its body mass ranges from 1.5 to $2.8 \mathrm{~kg}$ [15]. Due to characteristics such as adequate size, low maintenance cost and short gestation period rodents have been widely used as experimental models.

Vision is one of the crucial senses of agoutis. Small changes in visual acuity can make it difficult to find out food, locomotion, and defense of predators. The objective of this research was to establish presumably normal values for variables of ocular ultrasound in B-mode and pulsed doppler of agouti, which can be useful in clinical and surgical decisions for the species.

\section{MATERIALS AND METHODS}

\section{Animals}

Animals from the Center for Studies and Preservation of Wild Animals - NEPAS (Certificate of Registration of IBAMA / PI N ${ }^{\circ} 02$ / 08-618) of the Center of Agricultural Sciences CCA/UFPI were analyzed. Their accommodation is in collective stalls, they receive daily diet formulated by the responsible veterinarian and the water intake is ad libium. Data collection was performed at the Specialized Veterinary Diagnostic Imaging Center - NUDIVE/CCA-UFPI. As exclusion criteria, all 20 agoutis underwent clinical and ophthalmic examination to verify the anatomical integrity of the eye bulb and its general condition, as well as structural ocular changes during ultrasound examination, such as cataract and retinal changes. Only animals without clinical signs of eye disease and non-pregnant females were included in the study. Forty ocular bulbs of 20 adult rodents of the species $D$. prymnolopha were used, being 15 females and 5 males. The animals were captured and physically contained with the aid of a hunting net for later anesthesia.

\section{Chemical containment}

As protocol was followed the methodology described by Pessoa et al. [10], using a combination of ketamine hydrochloride ${ }^{1}(40 \mathrm{mg} / \mathrm{kg}$ ) and xylazina hydrochloride ${ }^{2}(1 \mathrm{mg} / \mathrm{kg})$, intramuscularly. The action of the drugs occurred about 10 min after application, and lasted 30 to $40 \mathrm{~min}$, with no need for reapplication or complications. After verifying the sedative effect of the drugs used, the animals were positioned on the examination table in sternal decubitus, for the ultrasound examination.

\section{B-mode ultrasound eye biometrics}

To obtain the data, the transpalpebral ultrasound technique was used [4], with a 5-8 MHz (C85) multifrequency convex transducer, connected to an ultrasound device ${ }^{3}$ (Philips $^{\circledR}$ HD15). All records were initiated by the left eye bulb and measurements taken by the same examiner. After identifying the structures, distances in millimeters $(\mathrm{mm})$ of anterior chamber thickness [distance between cornea and anterior lens capsule - D1], lens thickness [distance between anterior and posterior lens capsule - D2] were measured, thickness of the vitreous chamber [distance between the posterior lens capsule and the vitreoretinal interface - D3] and the axial length of the ocular bulb [distance from the cornea and the posterior wall of the ocular bulb - D4]. Measurement values were obtained from three consecutive measurements in each eye (mean).

\section{Evaluation of ophthalmic artery vascular flow}

The external ophthalmic artery was identified by Doppler signal on the optic nerve topography [4], and an angle parallel to the flow was used to obtain the resistivity index. The speed of the scales was adjusted, adjusting the pulse repetition frequencies for subsequent acquisition of the Doppler wave spectrum. All 
measurements were automatically calculated by the ultrasound equipment's own software.

\section{Statistical analysis}

The collected data were analyzed in the software Bioest 5.0 for Windows. Initially, the normal path was tested by the Shapiro-Wilk test, for each parameter, later, the paired t-test was performed, adopting a significance level of $5 \%(P<0.05)$.

\section{RESULTS}

The protocol used for chemical containment was satisfactory, allowing the examination to be performed properly to obtain satisfactory quality ultrasound images. Ultrasound examination allowed to obtain a panoramic view of B-mode sonographic image and pulsed-wave Doppler mode from the eyeball of the agoutis (Figure 1A and 1B). Because the small size of the ocular structures from agoutis, the highresolution zoom tool was used to properly characterize the anatomy of the eyeball (Figure 1C and 1D). Thus, it was possible to delimit the anatomical structures of the eyeball (anterior chamber, the lens and vitreous), based on their echogenic differences (Figure 1C). The external ophthalmic artery showed a slightly tortuous path originating from the anterior portion of the eyeball. The blood flow of the external ophthalmic artery was identified by color doppler. The Nyquist frequency to avoid aliasing and wall overflow signal was between speeds of -20 to $+20 \mathrm{~cm} / \mathrm{s}$, considering the color flow scale of the equipment (BART - blue away red towards). After adjusting the sample volume (gate) parallel to the flow direction on the vessel, a maximum doppler sign was obtained and the wave spectrum showing a parabolic and low resistance flux pattern (Figure 1B and 1D). The marked points on the spectrum in the Figure 1D define the calculations that derive the values from the resistivity index in Dasyprocta prymnolopha species.

All data obtained through ocular ultrasound examination of the agouti presented normal distribution. In the paired $t$-test for ocular measurements, in the comparison between the antimeres there was no statistical difference in the biometric values. The ocular biometric values obtained are described in Table 1. All samples from both eyes had a normal distribution. In the paired $t$-test for ocular measurements, in the comparison between the right and left eyeballs there was no statistical difference in the biometric values. There was no statistical difference between the eyes regarding the resistivity index of the external ophthalmic artery (Table 2). Correlation of axial length with lens thickness resulted in a 1:1.5 ratio.

Table 1. Mean values, standard deviation, $P$ value (bilateral) and confidence interval (CI) (95\%) for measurements of right and left agouti eyes (Dasyprocta prymnolopha), in millimeters (mm), anterior chamber thickness (D1), lens thickness (D2), vitreous thickness (D3) and axial length (D4), obtained by two-dimensional ultrasound, Teresina, PI, Brazil.

\begin{tabular}{|c|c|c|c|}
\hline & Variable & Right eyeball & Left eyeball \\
\hline \multirow{4}{*}{ D1 } & Average & $1.28 \mathrm{~mm}$ & $1.22 \mathrm{~mm}$ \\
\hline & DP & 0.3 & 0.1 \\
\hline & $P$ & 0.38 & \\
\hline & IC $95 \%$ & -0.08 a 0.21 & \\
\hline \multirow{4}{*}{ D2 } & Average & $8.27 \mathrm{~mm}$ & $8.11 \mathrm{~mm}$ \\
\hline & $\mathrm{DP}$ & 0.9 & 0.9 \\
\hline & $P$ & 0.40 & \\
\hline & IC $95 \%$ & -0.22 a 0.53 & \\
\hline \multirow{4}{*}{ D3 } & Average & $5.35 \mathrm{~mm}$ & $5.30 \mathrm{~mm}$ \\
\hline & $\mathrm{DP}$ & 0.48 & 0.41 \\
\hline & $P$ & 0.66 & \\
\hline & IC $95 \%$ & -0.18 a 0.28 & \\
\hline \multirow{4}{*}{ D4 } & Average & $12.7 \mathrm{~mm}$ & $13 \mathrm{~mm}$ \\
\hline & DP & 0.9 & 0.68 \\
\hline & $P$ & 0.2 & \\
\hline & IC $95 \%$ & -0.90 a 0.20 & \\
\hline
\end{tabular}


S.B. Araújo, F.R. Alves, G.T. Pessoa, et al. 2021. Ocular Echobiometry and Resistivity Index of External Ophthalmic Artery in Agoutis (Dasyprocta prymnolopha).

Acta Scientiae Veterinariae. 49: 1832.

Table 2. Mean resistivity (IR) values of the left and right external ophthalmic arteries of agoutis (Dasyprocta prymnolopha), Teresina, PI, Brazil.

\begin{tabular}{ccc}
\hline Variable & Right eyeball & Left eyeball \\
\hline Average & 0.4305 & 0.4258 \\
\hline DP & 0.0390 & 0.0387 \\
$P$ & 0.4076 & \\
\hline IC 95\% & -2.7332 a 2.1763 & \\
\hline
\end{tabular}
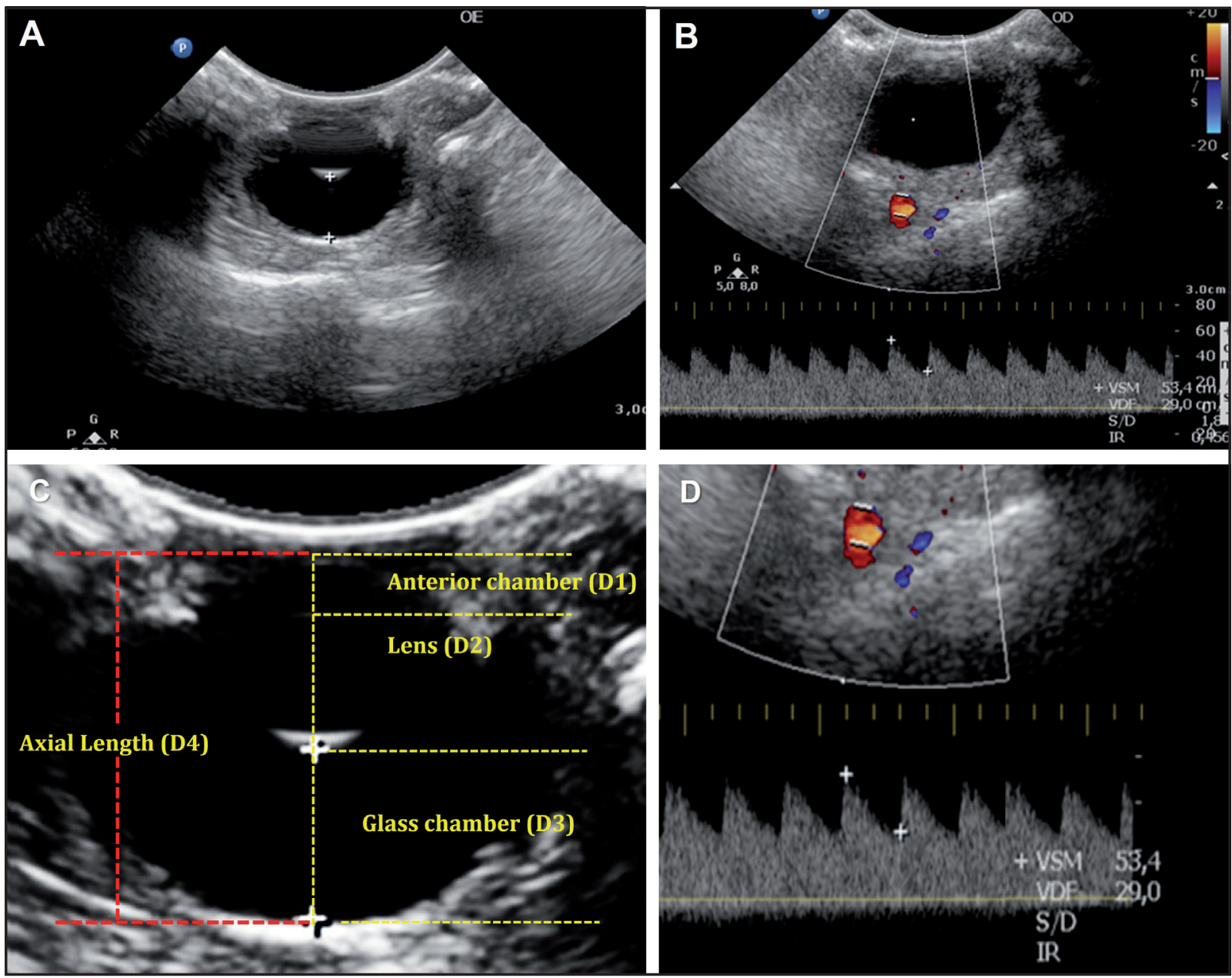

Figure 1. Ultrasound examination from the eye of Dasyprocta prymnolopha. A- \& B- Panoramic view of B-mode sonographic image from the eyeball and pulsed-wave Doppler mode. C- \& D- Represent an enlarged ultrasonographic view of the structures of the right eyeball of the species. The markings indicate the boundaries of each part of the eyeball. Interrogation of the external ophthalmic artery was evidenced. Note the wave spectrum showing low resistance flux pattern. The marked points on the spectrum define the calculations that derive the values from the resistivity index in Dasyprocta prymnolopha species.

\section{DISCUSSION}

In this study the use of the convex transducer was viable, promoting adequate contact with the ocular surface and images of satisfactory quality for measurements using a frequency of $8 \mathrm{MHz}$. In a study evaluating primate ocular biometry used a frequency transducer similar $(7.5-10 \mathrm{MHz})$ to characterize the ocular biometry in the studied species [16]. A higher frequency probe (20 MHz) was used to ultrasound ocular examination of wild canids 
(Cerdocyon thous) [11]. Although characteristics such as anatomical arrangement and superficiality of the ocular structures indicate the need for high frequency devices, it is possible to obtain echobiometry measurements using transducers with lower frequencies, even in smaller animals [13]. All echobiometric values were obtained by direct measurement of intraocular structures as was suggest reference values of the vitreous chamber in humans and dogs respectively, by calculating the difference between the axial length of the ocular bulb and the depth of the anterior chamber $[13,17]$.

The anterior chamber thickness values in this experiment did not differ statistically between the antimers. Similarly, when determining the ophthalmic parameters in dogs, did not observe statistical difference in this evaluation and found on average similar values to those described in this study [14].

The data obtained for lens thickness did not differ statistically for antimers, like that obtained for other rodent species evaluated with the same methodology $[2,3,8,18]$. On average, lens thickness values were $8.27 \mathrm{~mm}$ and $8.11 \mathrm{~mm}$ (right and left eyeball, respectively), a result superior to that observed in conventional laboratory rodents (rats and mice), chinchillas and rabbits $[3,19]$.

The mean values of the agouti vitreous chamber thickness were $5.35 \mathrm{~mm}$ and $5.30 \mathrm{~mm}$ (right and left, respectively). The values are like that were observed in chinchillas [6]. However, larger rodents, such as capybara, can present up to twice the observed values of agouti [7].

The axial length of the agouti eyeball was 12.7 $\pm 0.9 \mathrm{~mm}$ and $13 \pm 0.68 \mathrm{~mm}$ (right and left, respectively). The values are lower than those described in capybaras [18]. Conventional laboratory rodents (rats and mice) have a smaller ocular bulb size than that obtained in agoutis $[2,3,8]$.

The sonographic characteristics of the agouti eye are like those described in the literature in other domestic and wild animal species $[1,2,3,6,8,11,14,16,18]$. The correlation between the lens and the axial length of the eyeballs in the agouti was $1: 1.5$, lower than that described in other rodent species such as chinchillas (1:2), guinea pig (1:2), and rats $(1: 2,6)$, giving them the anatomical characteristic of small eyes and a large lens $[2,6,8]$. These lens, more spherical shaped, increase optical power especially near, as there is a reduction in traction suffered by the suspensory ligaments caused by ciliary muscles contraction, is an important feature for the species increased visibility, especially in the search for food.

In this study the external ophthalmic artery was characterized in all animals, however obtaining the spectral tracing was difficult. This vessel is a branch of the maxillary artery that derives from the external carotid artery. It is characterized by its fine caliber, thus the Doppler signal was lost at some moments, requiring maneuvers in the transducer positioning to obtain the appropriate angle. The mean resistivity values of the external ophthalmic artery were 0.4305 and 0.4258 (right and left eye, respectively), characterizing a low resistance. There was no statistical difference between the eyes, a result like that described in cats [5] but differing from what has been found in non-human primates such as the capuchin monkey [12]. In wild animals, and especially wild rodents, there is scarce data reporting on the ophthalmic artery resistivity, and there is a lack of studies, which may be justified by the behavioral characteristics of defense and the high susceptibility to stress in capture, since the performance of the technique requires, as in other procedures, the use of chemical containment [9].

\section{CONCLUSION}

Based on the results obtained, it can be concluded that ocular echobiometry and ophthalmic artery Doppler flowmetry in Dasyprocta prymnolopha species are feasible, if there is mastery of the examiner regarding the anatomy and appropriate technique. The values inferred here serve as an aid to veterinarians in the diagnosis of ophthalmopathies.

\section{MANUFACTURERS \\ ${ }^{1}$ Konig do Brasil Ltda. São Paulo, SP, Brazil. \\ ${ }^{2}$ Laboratórios Vencofarma do Brasil Ltda. Londrina, PR, Brazil. \\ ${ }^{3}$ Philips Medical Systems. Pembroke Pines, FL, USA.}

Ethical approval. This study was conducted after express authorization from the Federal University of Piaui's Ethics Committee (CEUA), under registration number 467/18, and approved by the Chico Mendes Institute for Biodiversity Conservation (ICMBIO), through the Biodiversity Authorization and Information System, number 61038-1.

Declaration of interest. The authors report no conflicts of interest. The authors alone are responsible for the content and writing of the paper. 


\section{REFERENCES}

1 Araújo N.L.L.C., Raposo A.C.S., Muramoto C., Meneses D.S., Bittencourt M.V., Martins Filho E.F. \& Oriá A.P. 2017. Evaluation of selected ophtalmic diagnostic tests in green iguanas (Iguana iguana). Journal of Exotic Pet Medicine. 26(3): 176-187.

2 Bantseev V., Oriowo O.M., Giblin F.J., Leverenz V.R., Trevithick J.R. \& Sivak J.G. 2004. Effect of hyperbaric oxygen on guinea pig lens optical quality and on the refractive state of the eye. Experimental Eye Research. 78(5): 925-931.

3 Barathi V.A., Boopathi V.G., Yap E.P. \& Beuerman R.W. 2008. Two models of experimental myopia in the mouse. Vision Research. 48(7): 904-916.

4 Carvalho C.F., Dupré A.S.A. \& Perez R.B. 2009. Ultrassonografia Doppler ocular. In: Carvalho C.F. (Ed). Ultrassonografia Doppler em Pequenos Animais. São Paulo: Roca, pp.152-157.

5 Gonçalves G.F., Pippi N.L., Leme M.C., Custódio A.T., Silva A.V., Romagnolli P., Pachaly J.P., Bottin J.M.P. \& Livero F.A.R. 2008. Correlação entre a pressão arterial média e o fluxo sanguíneo na artéria oftálmica externa em gatos (Fellis catus, Linnaeus, 1758). Brazilian Journal of Veterinary Research and Animal Science. 45(1): $57-66$.

6 Lima L., Montiani-Ferreira F., Tramontin M.H., Santos L.L., Machado M., Lange R.R. \& Russ H.H.A. 2010. The chinchilla eye: morphologic observations, echobiometric findings and reference values for selected ophthalmic diagnostic tests. Veterinary Ophthalmology. 13(1): 14-25.

7 Montiani-Ferreira F., Truppel J., Tramontin M.H., Vilani R.G.D. \& Lange R.R. 2008. The capybara eye: clinical tests, anatomic and biometric features. Veterinary Ophthalmology. 11(3): 386-394.

8 Mutti D.O., Zadnik K. \& Murphy C.J. 1998. The effect of continuous light on refractive error and the ocular components of the rat. Experimental Eye Research. 67(3): 631-636.

9 Pachaly J.R., Monteiro Filho E.L.A., Werner P.R., Giovanelli D.F., Conti J.B., Wosiacki S.R., Belettini S.T. \& Voltarelli-Pachaly E.M. 2014. Cetamina, xilazina e atropina, em doses calculadas por extrapolação alométrica interespecífica para contenção farmacológica da cutia (Dasyprocta azarae). Arquivos de Ciências Veterinárias e Zoologia. 17(1): 11-26.

10 Pessoa G.T., Sousa F.C.A., Rodrigues R.P.S., Moura L.S., Sanches M.P., Ambrósio C.E., Silva A.B.S. \& Alves F.R. 2008. Abdominal B-mode and Doppler ultrasonography of chemically restrained agouti (Dasyprocta prymnolopha, Wagler, 1831). Pesquisa Veterinária Brasileira. 38(4): 785-793.

11 Renzo R. 2015. Parâmetros oftálmicos em cachorro-do-mato (Cerdocyon thous, Linnaeus, 1766). 73f. Botucatu, SP. Tese (Doutorado em Cirurgia Veterinária) - Programa de Pós-Graduação em Cirurgia Veterinária, Faculdade de Ciências Agrárias e Veterinária.

12 Rodas N.R. 2014. Biometria ocular ultrassonográfica e dopplerfluxometria das artérias oftálmica interna e central da retina em macaco-prego (Sapajus spp.). 93f. Botucatu, SP. Dissertação (Mestrado em Medicina Veterinária e Zootecnia) - Programa de Pós-Graduação Medicina Veterinária e Zootecnia, Faculdade de Medicina Veterinária e Zootecnia - Universidade Estadual Paulista.

13 Shufelt C., Fraser-Bell S., Ying-Lai M., Torres M. \& Varma R. 2005. Refractive error, ocular biometry and lens opalescence in an adult population: The Los Angeles Latino eye study. Clinical and Epidemiologic Research. 46(12): 4450-4460.

14 Silva E.G., Pessoa G.T., Moura L.S., Guerra P.C., Rodrigues R.P.S., Sousa F.C.A., Ambrósio C.E. \& Alves F.R. 2018. Biometric, B-mode and color Doppler ultrasound assessment of eyes in healthy dogs. Pesquisa Veterinária Brasileira. 38(3): 565-571.

15 Silva F. 1984. Mamíferos Silvestres do Rio Grande do Sul. Porto Alegre: Fundação Zoobotânica do Rio Grande do Sul, pp.171-209.

16 Souza L.P., Merlini N.B., Bortolini, Z., Muller T.R., Teixeira C.R., Luciani M.G., Souza D.S. \& Vulcano L.C. 2018. Aspectos ultrassonográficos, biometria e dopplerfluxometria ocular do bugio ruivo (Alouatta fusca) Ultrasonography aspects, biometry and Doppler of howler monkey (Alouatta fusca). Pesquisa Veterinária Brasileira. 38(5): 1005-1013. 
S.B. Araújo, F.R. Alves, G.T. Pessoa, et al. 2021. Ocular Echobiometry and Resistivity Index of External Ophthalmic Artery in Agoutis (Dasyprocta prymnolopha). Acta Scientiae Veterinariae. 49: 1832.

17 Squarzoni R. 2011. Biometria ocular e sua relação com sexo, idade, tamanho e peso em cães da raça Cavalier King Charles Spaniel. 96f. Botucatu, SP. Tese (Doutorado em Medicina Veterinária e Zootecnia) - Programa de Pós-Graduação em Medicina Veterinária e Zootecnia, Universidade de São Paulo.

18 Tramontini M.H. 2010. Contribuição ultrassonográfica na avaliação de bulbos oculares de animais domésticos e selvagens. 67f. Curitiba, PR. Dissertação (Mestrado em Ciências Veterinárias) - Programa de Pós-Graduação em Ciências Veterinárias, Universidade Federal do Paraná.

19 Valinhos M.A.R., Ranzani J.J.T., Rodrigues A.C.L. \& Brandão C.V.S. 2012. Mensurações do bulbo ocular e cálculo do poder dióptrico de lentes intraoculares em coelhos. Arquivo Brasileiro de Medicina Veterinária e Zootecnia. 64(1): 58-62. 